\title{
Hybrid approaches in the treatment of aortic arch aneurysms: Postoperative and midterm outcomes
}

Joseph Bavaria, MD Prashanth Vallabhajosyula, MD, MS, Patrick Moeller, BS, Wilson Szeto, MD, Nimesh Desai, MD, PhD, and Alberto Pochettino, MD

Background: The combined open surgical and endovascular approach for the treatment of aortic arch aneurysms has emerged as a safe treatment modality. This platform may have an especially important role in treating patients of old age and with a greater comorbid burden. We describe our institutional experience with the hybrid aortic arch approach, with midterm outcomes.

Methods: From 2005 to the present, 685 patients have undergone thoracic endovascular repair (TEVAR); 104 had a hybrid arch repair (open plus endovascular approach). Of these, 47 patients had treatment for an aortic arch aneurysm with or without a proximal ascending aortic aneurysm. All these patients had a median sternotomy approach for arch vessel debranching and antegrade with or without retrograde TEVAR stent grafting of the arch. Results from a prospectively maintained database are reported.

Results: Twenty-eight patients had type I repair, 8 patients had type II repair, and 11 patients had type III arch hybrid repair. Those with type III repair were excluded from the analysis. Stent graft deployment rate was $100 \%$ after arch vessel debranching. Mean age was $71 \pm 8$ years. Fourteen percent of cases involved a redo sternotomy. Average cardiopulmonary bypass time was $215 \pm 64$ minutes, with a crossclamp time of $70 \pm 55$ minutes and a circulatory arrest time of $19 \pm 10$ minutes. The paraplegia rate was $5.5 \%(\mathrm{n}=2)$, with a stroke rate of $8 \%$ $(\mathrm{n}=3)$. In-hospital mortality was $8 \%(\mathrm{n}=3)$. There were no postoperative endoleaks. The mean length of stay was $17.2 \pm 14$ days. The median follow-up was $30 \pm 21$ months. Freedom from all-cause mortality was $71 \%, 60 \%$, and $48 \%$ at 1,3 , and 5 years, respectively. The aortic reoperation rate was $2.7 \%(n=1)$. No patient has a type 1 or 3 endoleak at latest follow-up.

Conclusions: The hybrid approach to aortic arch aneurysm involving a zone 0 stent graft landing can be safely adopted with good midterm results in a cohort of old patients with significant comorbidity. This procedure can be performed with no type 1 or 3 endoleaks and may represent a technical advancement in the field of aortic arch surgery. (J Thorac Cardiovasc Surg 2013;145:S85-90)

The management of aortic arch aneurysms remains a clinical challenge. Open total arch procedures can be accomplished using complex circulatory management and adjunct cerebral protection, but subgroups with multiple comorbidities may still experience significant morbidity and mortality from both neurologic and cardiovascular complications. ${ }^{1-3}$ In these high-risk patients, alternative therapies are sought. The introduction and regulatory approval of thoracic endovascular repair (TEVAR) for descending aortic disease has seen its application to many off-label uses, including aortic dissection, ${ }^{4,5}$ traumatic

\footnotetext{
From the Division of Cardiovascular Surgery, University of Pennsylvania Medical Center, Philadelphia, Pa.

Disclosures: Drs Bavaria, Vallabhajosyula, Moeller, Szeto, Desai, and Pochettino have nothing to disclose with regard to commercial support.

Read at The American Association for Thoracic Surgery Aortic Symposium,

New York, New York, April 26-27, 2012.

Received for publication Oct 12, 2012; accepted for publication Nov 20, 2012; available ahead of print Dec 26, 2012.

Address for reprints: Joseph Bavaria, MD, Hospital of the University of Pennsylvania, Division of Cardiovascular Surgery, Philadelphia, PA 19104 (E-mail: joseph. bavaria@uphs.upenn.edu).

$0022-5223 / \$ 36.00$

Copyright (C) 2013 by The American Association for Thoracic Surgery

http://dx.doi.org/10.1016/j.jtcvs.2012.11.044
}

transection, ${ }^{6}$ infection/fistula, and penetrating atherosclerotic ulcers. ${ }^{7,8}$ This application has been extended to the use of TEVAR for stenting the aortic arch with open great vessel debranching. The "hybrid" aortic arch repair, with debranching and reimplantation, or with bypass of aortic arch vessels and TEVAR with endografting of the aortic arch, is evolving toward a front-line treatment option for complicated pathologic conditions of the aortic arch, ${ }^{9-11}$ especially in patients with a severe comorbid status.

Combining open surgical and endovascular techniques, the hybrid arch repair seeks to limit operative, bypass, and circulatory arrest times by simplifying and shortening the arch repair. The arch hybrid concept entails reimplantation or bypass of all aortic arch vessels, and TEVAR implantation landing proximally in "zone 0" (ascending aorta-innominate origin), which is either suitable for use as a landing zone natively or has been replaced with a Dacron graft to construct an artificial landing zone (Figure 1). Multiple studies have demonstrated the feasibility of this approach to the aortic arch, demonstrating acceptable mortality and morbidity. ${ }^{9-11}$ We report our institutional experience with the arch hybrid operation, with midterm follow-up on these patients. 


\section{Abbreviations and Acronyms \\ $\mathrm{CPB}=$ cardiopulmonary bypass \\ CTA = computed tomography angiogram \\ NIRS = near-infrared spectroscopy \\ TEVAR $=$ thoracic endovascular repair}

\section{METHODS}

From 2005 to the present, 685 patients have undergone TEVAR at our institution. Of these, 104 underwent TEVAR for proximal aortic repair: 57 ascending/hemiarch replacements with antegrade stenting of the descending aorta for DeBakey type I dissection and 47 hybrid arch debranching procedures. The variations of these repairs can be classified as types I, II, and III.

\section{Type I Hybrid Arch}

Twenty-eight patients had a type I hybrid arch repair, in which there is an isolated arch aneurysm with good native landing zones (zone 0 and zone 3/4). Type 1 repair consists of reimplantation of the aortic arch vessels using a 4-branched Dacron graft, which is sewn to the native ascending aorta just above the sinotubular junction (Figure 1). This can be done without cardiopulmonary bypass (CPB) using a side-biting clamp in hemodynamically stable patients if the aorta is not calcified, but it can also be done on CPB with or without a short aortic crossclamp time.

If there is concern that the exposure of the left subclavian artery will be difficult via a median sternotomy, a preemptive left subclavian-left common carotid bypass is an option, and only innominate and left common carotid arteries are then reimplanted into the ascending aorta. After the arch debranching is complete, stent grafts can then be deployed via the fourth limb of the graft into the aortic arch. ${ }^{12}$ In some patients, endograft implantation is delayed and the stent graft is deployed later during the same hospital stay via a retrograde iliofemoral approach. If a carotid-subclavian bypass is performed, it is critical that the proximal left subclavian artery be ligated or coiled to prevent a type II (branch vessel) endoleak on aortic arch stenting. Recently, when a subclavian branch is necessary, we have been placing it into the extrathoracic subclavian artery via the second intercostal space in the left side of the chest.

\section{Type II Hybrid Arch}

Eight patients underwent a type II hybrid arch repair. This is undertaken in patients with proximal extension of aneurysmal disease into the ascending aorta, making the native aorta unsuitable for a zone 0 stent graft landing. This can be addressed by replacing the ascending aorta, creating a Dacron ascending zone 0 . At our institution, ascending aorta replacement, or a type II hybrid arch solution, is undertaken for a zone 0 diameter greater than $3.7 \mathrm{~cm}$, inasmuch as we and others have noted an increased risk of retrograde type A dissection in the deployment of proximal stent grafts when the ascending aortic diameter is greater than $4 \mathrm{~cm}$.

Type II arch hybrid operations require $\mathrm{CPB}$ and sometimes a brief interval of circulatory arrest for proximal aortic reconstruction, which can be done using either retrograde or selective antegrade perfusion strategies. After arch debranching and reconstruction of zone 0 with an ascending aortic graft, the endograft can be deployed through the arch with a Dacron zone 0 landing zone.

\section{Type III Hybrid Arch}

Eleven patients underwent type 3 hybrid arch repairs: a total arch replacement with a descending elephant trunk, combined with a delayed second-stage retrograde TEVAR repair, for extensive aortic diseases such as "mega-aorta" syndrome. Type 3 hybrid arch repairs are not classic hybrid arch repair procedures. All patients had either selective antegrade perfusion or a combination of antegrade and retrograde cerebral perfusion during the circulatory arrest period. These patients are not included in further analysis owing to significant differences in patient population, disease process, and most important, operative technique, inasmuch as the TEVAR solution is not into zone 0 .

In all cases, the patient was deemed unsuitable for traditional open repair owing to age or other comorbidities. Patients were preoperatively evaluated with a multislice computed tomography angiogram (CTA). CTA images were processed into 3-dimensional images by an outside service (M2S, West Lebanon, NH) for preoperative planning and proper sizing of endografts deployed in the arch. Surgery was performed in the hybrid operating room equipped with a universal floor-mounted angiographic $\mathrm{C}$-arm system for fluoroscopic guidance during and after endograft deployment.

Intraoperative transesophageal echocardiography was used in all cases. All patients also underwent at least one form of intraoperative neuromonitoring: intraoperative electroencephalogram, somtasensory-evoked potentials, and when available, cerebral oximetry using near-infrared spectroscopy.

\section{Statistical Analysis and Follow-up Methods}

All statistical comparisons were done using SPSS 19 (SPSS Inc, Chicago, Ill). Categorical variables were compared using Fisher's exact test. Continuous variables were compared using the Student $t$ test. Long-term survival was monitored through the national Social Security Death Index and cumulative survival was calculated using Kaplan-Meier analysis. All patients were followed up postoperatively with regular contrast CTA imaging (at discharge, 30 days, 6 months, and yearly). Follow-up was $100 \%$ in all groups. Institutional review board approval was obtained.

\section{RESULTS}

From 2005 to the present, 36 type I and II hybrid arch operations were performed at the hospital of the University of Pennsylvania. Mean age was $70.7 \pm 8$ years; $23(64 \%)$ were male (see Table 1 for demographics). Forty-two percent of the patients had prior stroke, $33 \%$ had previous myocardial infarction, and $81 \%$ had some history of smoking. Twenty-nine $(81 \%)$ had aneurysmal disease of the aortic arch (mean aortic diameter, $7.1 \pm 1.5 \mathrm{~cm}$ ). Four had chronic aortic dissection; 2 had pseudoaneurysm of the aortic arch secondary to remote traumatic transection, and 1 had proximal degeneration in the setting of prior TEVAR (for descending aortic aneurysm). Surgical history (Table 2) included coronary artery bypass grafting $(\mathrm{n}=3)$, patent foramen ovale repair $(\mathrm{n}=1)$, type A dissection repair via sternotomy approach $(\mathrm{n}=1)$, and thoracoabdominal aortic aneurysm repair $(n=1)$. Two patients had prior thoracic aortic endograft repairs: 1 had proximal degeneration of the prior repair, and 1 had a new unrelated saccular aneurysm in the mid arch.

Of the 28 type I hybrid arch repairs, 16 (57\%) were done off $\mathrm{CPB}$ using a side-biting clamp on the ascending aorta for great vessel debranching. Twelve were done on CPB, with a mean time of $193 \pm 58$ minutes and a mean aortic crossclamp time of $44 \pm 27$ minutes. In $18(64 \%)$ patients the 


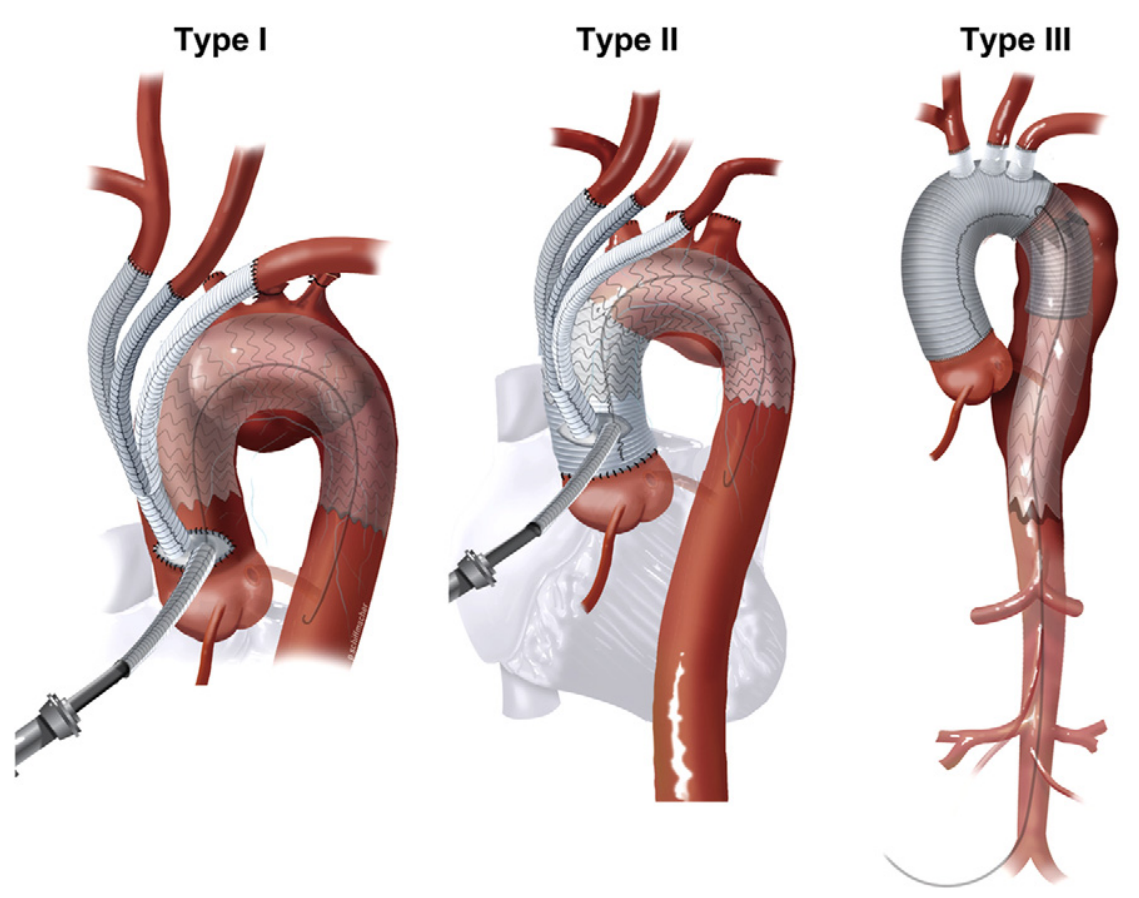

FIGURE 1. Hybrid aortic arch repair, types I, II, and III.

TEVAR graft was deployed antegradely through the fourth limb of the aortic graft; 7 (25\%) patients had concurrent retrograde TEVAR via the iliofemoral approach. Three $(11 \%)$ patients did not have endografting during the same operation, but later in the same hospital stay using iliofemoral access. See Table 3 for a full enumeration of the intraoperative variables.

Eight patients did not have a suitable zone 0 for implantation of a thoracic endograft. In these patients, the ascending aorta was replaced to create a Dacron zone

TABLE 1. Patient demographics

\begin{tabular}{lccc}
\hline & All hybrids & Type 1 & Type 2 \\
\hline Preoperative characteristics & & & \\
N & 36 & 28 & 8 \\
Age (y) & $70.7 \pm 8.0$ & $69.3 \pm 7.5$ & $71.1 \pm 8.3$ \\
Gender (N male) & $23(64 \%)$ & $18(64 \%)$ & $5(63 \%)$ \\
Prior CVA & $15(42 \%)$ & $12(43 \%)$ & $3(38 \%)$ \\
Chronic lung disease & $14(39 \%)$ & $11(39 \%)$ & $3(38 \%)$ \\
Prior MI & $12(33 \%)$ & $9(32 \%)$ & $3(38 \%)$ \\
Chronic renal insufficiency & $6(17 \%)$ & $6(21 \%)$ & $0(0 \%)$ \\
Smoker (current or history) & $29(81 \%)$ & $23(82 \%)$ & $6(75 \%)$ \\
Aortic disease & & & \\
Aneurysm & $29(81 \%)$ & $25(89 \%)$ & $5(63 \%)$ \\
Maximum diameter (mean, cm) & $7.1 \pm 1.5$ & $7.1 \pm 1.5$ & $7.4 \pm 1.4$ \\
Chronic dissection & $4(11 \%)$ & $1(4 \%)$ & $3(38 \%)$ \\
Failure of prior TEVAR & 1 & 1 & \\
Pseudoaneurysm (posttraumatic & $2(6 \%)$ & $2(7 \%)$ & \\
$\quad$ transection) & & & \\
\hline
\end{tabular}

$C V A$, Cerebrovascular accident; $M I$, myocardial infarction; TEVAR, thoracic endovascular repair.
0 landing zone. Therefore, these patients required full CPB and a short period of circulatory arrest for a simple open distal anastomosis, using both antegrade and retrograde cerebral perfusion strategies. Mean CPB time was $259 \pm 54$ minutes; mean crossclamp time was $121 \pm 63$ minutes. Mean circulatory arrest time for distal anastomosis was $19 \pm 10$ minutes, with an additional $45 \pm 13 \mathrm{~min}$ utes of selective antegrade cerebral perfusion for arch debranching.

Thirty-day/in-hospital mortality was $3(8 \%)$ of 36 for the entire group (Table 4). Mortality was $11 \%(n=3)$ in the type I group and $0 \%$ in the type II group. Causes of death were all secondary to neurologic complications: 2 from spinal ischemia resulting in permanent paraplegia and 1 from complications of stroke. Although there have been no inhospital deaths to date in patients with type II hybrid arch repairs, mortality and all other immediate postoperative

TABLE 2. Surgical history

\begin{tabular}{lccc}
\hline \multicolumn{1}{c}{ Surgical history } & All hybrids & Type 1 & Type 2 \\
\hline $\mathrm{N}$ & 36 & 28 & 8 \\
Redo sternotomy & $5(14 \%)$ & $4(14 \%)$ & $1(13 \%)$ \\
CABG & $3(8 \%)$ & $2(7 \%)$ & $1(13 \%)$ \\
Type A dissection repair & $1(3 \%)$ & $1(4 \%)$ & \\
PFO closure & $1(3 \%)$ & $1(4 \%)$ & \\
TEVAR & $2(6 \%)$ & $1(4 \%)$ & $1(13 \%)$ \\
TAAA & $1(3 \%)$ & $1(4 \%)$ & \\
AAA (open or EVAR) & $5(14 \%)$ & $4(14 \%)$ & $3(38 \%)$ \\
\hline
\end{tabular}

$C A B G$, Coronary artery bypass grafting; $P F O$, patent foramen ovale; TEVAR thoracic endovascular repair; TAAA, thoracoabdominal aortic aneurysm; $A A A$, abdominal aortic aneurysm; $E V A R$, endovascular repair. 
TABLE 3. Intraoperative variables

\begin{tabular}{lccc}
\hline \multicolumn{1}{c}{ Intraoperative } & All hybrids & Type 1 & Type 2 \\
\hline $\mathrm{N}$ & 36 & 28 & 8 \\
Off pump & $16(44 \%)$ & $16(57 \%)$ & \\
CPB time (m) & $215 \pm 64$ & $193 \pm 58$ & $259 \pm 54$ \\
Aortic crossclamp time (m) & $70 \pm 55$ & $44 \pm 27$ & $121 \pm 63$ \\
Circulatory arrest & $7(19 \%)$ & & $7(87 \%)$ \\
Circulatory arrest time (total, m) & & & $19 \pm 10$ \\
SACP time for arch debranching (m) & & $25.0 \pm 13$ \\
Number of stents implanted (median) & 2 & 1.5 \\
Adjunct CABG & $7(19 \%)$ & $6(21 \%)$ & $1(13 \%)$ \\
Adjunct valve repair/replace & $2(6 \%)$ & $1(4 \%)$ & $1(13 \%)$ \\
Two-branch reimplantation with & $8(22 \%)$ & $7(25 \%)$ & $1(13 \%)$ \\
$\quad$ carotid-left subclavian bypass & & & \\
\hline CPB, Cardiopulmonary bypass; $S A C P$, selective antegrade cerebral perfusion; $C A B G$, & \\
coronary artery bypass grafting. & & &
\end{tabular}

outcomes showed no significant difference between the 2 hybrid arch types (Table 4). Two $(6 \%)$ of 36 patients had permanent paraplegia/paraparesis postoperatively, with an additional $5(14 \%)$ of 36 having mild fully reversed transient neurologic events. Importantly, both cases of permanent paraplegia occurred during the first year of adopting this surgical modality.

Late type 2 endoleak (branch vessel) occurred in 1 patient, noted 3 years postoperatively. This patient had a type 1 hybrid arch repair for proximal degeneration of a prior TEVAR repair (with additional distal TEVAR for a distal type 1 endoleak in the same operation) and did not have full relining of the prior endograft repair. This patient did not undergo reintervention and died 6 years after the operation.

Follow-up was $30 \pm 21$ months. Late freedom from allcause mortality was $71 \%, 60 \%$, and $48 \%$ at 1,3 , and 5 years ( $\mathrm{N}$ at risk $=22,10$, and 4 ), with 16 late patient deaths: all but 1 occurred in the type 1 hybrid group (Figure 2). Cumulative survival at 1 year for type II hybrids was $87 \%(\mathrm{~N}$ at risk $=3)$, better than type I hybrids $(68 \% ; \mathrm{N}$

TABLE 4. Postoperative outcomes

\begin{tabular}{lcccc}
\hline \multicolumn{1}{c}{ Outcomes } & All hybrids & Type 1 & Type 2 & $\begin{array}{c}P \text { (type 1 } \\
\text { vs type 2) }\end{array}$ \\
\hline $\mathrm{N}$ & 36 & 28 & 8 & \\
In-hospital mortality & $3(8 \%)$ & $3(11 \%)$ & 0 & .45 \\
Stroke & $3(8 \%)$ & $3(11 \%)$ & 0 & .45 \\
Permanent paraplegia & $2(6 \%)$ & $2(7 \%)$ & 0 & .6 \\
Transient heurologic & $5(14 \%)$ & $3(11 \%)$ & $2(25 \%)$ & .3 \\
$\quad$ deficit & & & & \\
Renal failure & $3(8 \%)$ & $3(11 \%)$ & 0 & .45 \\
Renal failure requiring & $1(3 \%)$ & $1(4 \%)$ & 0 & .78 \\
$\quad$ new hemodialysis & & & & \\
Reoperation for bleeding & $1(3 \%)$ & $1(4 \%)$ & 0 & .78 \\
Atrial fibrillation & $15(42 \%)$ & $11(39 \%)$ & $4(50 \%)$ & .44 \\
Mean hospital stay (d) & $17.2 \pm 14.0$ & $16.3 \pm 14.0$ & $22.0 \pm 9.6$ & .28 \\
\hline
\end{tabular}

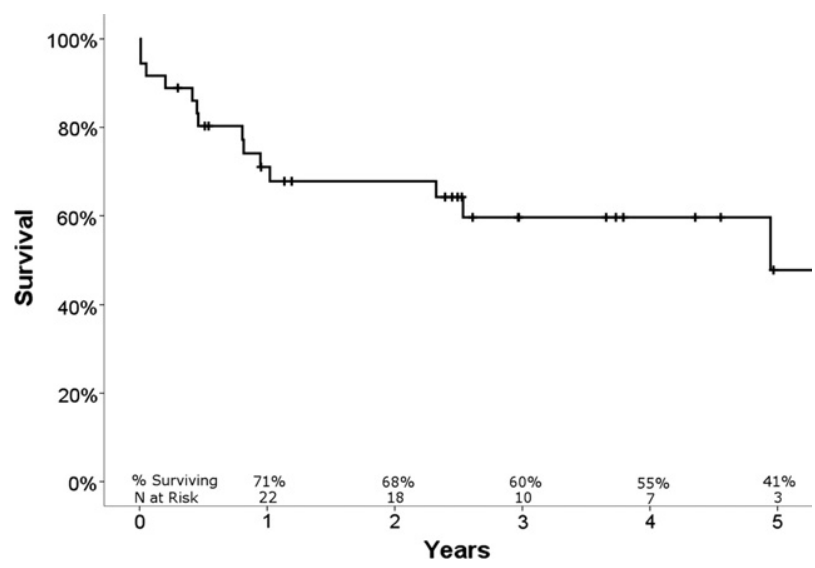

FIGURE 2. Midterm follow-up outcomes in type I and type II hybrids. Mean follow-up, $30 \pm 21$ months. Late stroke and endoleak rate, $0 \%$. Aortic reoperation rate, $2.7 \%$.

at risk $=19)$. Again, this difference did not rise to the level of statistical significance $(P=.244)$. The aortic reoperation rate was $1(2.8 \%)$ of $35: 1$ patient required a reintervention for a retrograde type A dissection 155 days after a type I hybrid repair; the second repair was tolerated with no complications. Importantly, this single retrograde type A dissection was with a 42-mm barbed endograft for an ascending aortic diameter larger than $38 \mathrm{~mm}$, which in our present algorithm is contraindicated unless a type II repair is performed.

\section{DISCUSSION}

Hybrid approaches for the treatment of aortic arch aneurysmal disease are being performed with increasing frequency. This is a reflection of the increasing comfort level of cardiovascular surgeons with endovascular technology and the improving technology of endovascular platforms, which permit successful landing of stent grafts in the proximal thoracic aorta. As the technology improves, it will be critical for the cardiovascular surgeon to be trained in advancing the field of hybrid aortic arch and ascending aorta operations. In addition, as the patient population with thoracic aortic disease seeking intervention gets older and older, embracing and honing these skills will be crucial. Although there is mounting evidence to suggest an important role for the hybrid approach for treating aortic arch disease, to this day there are no randomized trials or large nonrandomized studies comparing hybrid arch procedures with conventional open surgical approaches. Interpretation of what data exist must be viewed in this context.

In addition to the operative mortality associated with complex operations such as aortic arch hybrid procedures, the Achilles heel of this intervention remains neurologic complications. Several groups have shown that arch hybrid procedures can be performed with acceptable mortality, with a very minimal postoperative and long-term endoleak 
rate. ${ }^{9-11,13-16}$ However, neurologic complications, including stroke and spinal cord ischemia, remain a significant cause of morbidity and associated mortality in this cohort of patients. In a systematic review of hybrid arch operations in 1886 patients, pooled mortality was $10.8 \%$, with $15.1 \%$ mortality in diseases that extended to the ascending aorta. ${ }^{13}$ Pooled stroke risk was $7 \%$, with a pooled spinal cord ischemia rate of $7 \%$, with no difference seen with respect to the extent of proximal ascending aortic involvement. In our series of 36 patients, mortality was $8 \%$ $(\mathrm{n}=3)$, with all deaths seen in the type I hybrid arch group. Eight patients undergoing type II hybrid repair had no mortality.

The stroke rate was $8 \%$, with a paraplegia rate of $5.5 \%$. All 3 deaths in the cohort had associated neurologic complications ( 2 with paraplegia; 1 with stroke), underlying the significant morbidity and mortality associated with these devastating complications in aortic arch surgery. Of note, $42 \%$ of the patients in our study had a preoperative history of stroke. Twenty-nine of the 36 patients had atherosclerotic aneurysms, with $52 \%$ of the patients having high-grade atheroma or mobile atheroma. Atherosclerotic disease is a predictor of perioperative stroke, and the large cohort of patients with prior stroke and high-grade atheroma attests to the level of comorbid status in the arch hybrid group. ${ }^{17,18}$ When we compared our arch hybrid and open surgical arch cohorts, the rate of high-grade (grade $\geq 3$ ) or mobile atheroma was significantly higher in the hybrid group $(48 \%$ vs $6 \%$ ). Several groups report stroke rates up to $12 \%$ in patients undergoing total arch repair of atherosclerotic aneurysms. ${ }^{3,11,17-19}$ Our study, in addition to others, suggests that the hybrid arch approach to atherosclerotic aneurysmal arch disease can be safely adopted with neurologic outcomes at least equivalent to those of conventional open repair.

A complication unique to the hybrid aortic arch cohort of patients, unlike the conventional open group, is the occurrence of endoleak. The reporting of endoleak rates with hybrid arch repair is not very thorough, with long-term follow-up data virtually absent. Endoleak rates have ranged from $0 \%$ to $15 \%{ }^{9-12,16-18}$ Similar to TEVAR, hybrid arch operations with type I and III endoleaks are associated with greater morbidity than those seen with type II endoleaks. In an article by Kotelis and associates, ${ }^{14}$ patients undergoing hybrid arch repair with zone 0 proximal landing had lower endoleak rates than with zone 1 landing. At our institution, we do not perform zone 1 proximal landing. All arch aneurysms are treated with zone 0 landing. In this study, the intraoperative endoleak rate was $5(13.8 \%)$ of 36 . All these patients underwent further endovascular reintervention with a resulting postoperative endoleak rate of $0 \%$. On late follow-up, 1 patient had a retrograde type A dissection develop from the proximal landing zone site. This case was undertaken during our fourth year of arch hybrid operations, with the use of a TX2 device (Cook Medical, Bloomington, Ind). After this experience, we have stopped using the TX2 stent graft device for arch hybrid operations. We have adopted primarily the use of the Gore TAG device (W. L. Gore \& Associates, Inc, Flagstaff, Ariz) and at times the Valiant device (Medtronic, Inc, Minneapolis, Minn). Since this switch, we have not had a retrograde type A dissection, and we have had no distal type B dissections in the arch aneurysm cases. In other series, in patients with endoleak, the aortic reoperation rate is increased. Our aortic reoperation rate is $1(2.7 \%)$ of 36 (a retrograde type A dissection with the use of the TX2 device proximally) during the median midterm follow-up of 30 months.

Eight patients in this study underwent type II arch hybrid repair. Owing to the required ascending aortic reconstruction, all these patients had a period of circulatory arrest. Even though these patients had a more complex operation, postoperative and midterm outcomes in these patients have been excellent. Postoperative mortality, stroke, paraplegia, and endoleak rates were all $0 \%$. One patient died during follow-up. Inasmuch as these cases were performed more recently, this may be a reflection of the increasing experience we gained with the hybrid arch platform. In line with this idea, since our first year of hybrid arch operations, the paraplegia and aortic reoperation rates have remained at $0 \%$ in the type I arch hybrid group as well, with a single postoperative death since then.

\section{CONCLUSIONS}

The hybrid approach to the treatment of aortic arch aneurysm continues to evolve, with an increasingly important role especially in patients with a high comorbid index and old age. On the basis of the arch and ascending aortic anatomy, this procedure can be performed without CPB. Midterm follow-up on these patients has shown that the technique can be safely adopted with a low aortic reoperation rate and with no delayed stroke and endoleak. The type II arch hybrid, which involves greater complexity, can also be safely adopted with good midterm outcomes. Further follow-up will attest to the validity of this technique in aortic arch surgery.

\section{References}

1. Svensson LG, Kim KH, Blackstone EH, Alster JM, McCarthy PM, Greenberg RK, et al. Elephant trunk procedure: newer indications and uses. Ann Thorac Surg. 2004;78:109-16.

2. Svensson LG, Crawford ES, Hess KR, Coselli JS, Raskin S, Shenaq SA, et al. Deep hypothermia with circulatory arrest: determinants of stroke and early mortality in 656 patients. J Thorac Cardiovasc Surg. 1993;106:19-28.

3. Sundt TM, Orszulak TA, Cook DJ, Schaff HV. Improving results of open arch replacement. Ann Thorac Surg. 2008;86:787-96.

4. Zeeshan A, Woo EY, Bavaria JE. Thoracic endovascular repair for acute complicated type B aortic dissection: superiority relative to conventional open surgical and medical therapy. J Thorac Cardiovasc Surg. 2010;140(6 suppl):S109-15 discussion S142-6. 
5. Pochettino A, Brinkman WT, Moeller P, Szeto WY, Moser W, Cornelius K, et al. Antegrade thoracic stent grafting during repair of acute DeBakey I dissection prevents development of thoracoabdominal aortic aneurysms. Ann Thorac Surg. 2009;88:482-9; discussion 489-90.

6. Neschis DG, Moainie S, Flinn WR, Scalea TM, Bartlett ST, Griffith BP. Endograft repair of traumatic aortic injury - a technique in evolution: a single institution's experience. Ann Surg. 2009;250:377-82.

7. Szeto WY, Moser WG, Desai ND, Milewski RK, Cheung AT, Pochettino A, et al. Transapical deployment of endovascular thoracic aortic stent graft for an ascending aortic pseudoaneurysm. Ann Thorac Surg. 2010;89:616-8.

8. Metcalfe MJ, Karthikesalingam A, Black SA, Loftus IM, Morgan R, Thompson MM. The first endovascular repair of an acute type A dissection using an endograft designed for the ascending aorta. J Vasc Surg. 2012 Jan;55: 220-2.

9. Bavaria J, Milewski RK, Baker J, Moeller P, Szeto W, Pochettino A. Classic hybrid evolving approach to distal arch aneurysms: toward the zone zero solution. J Thorac Cardiovasc Surg. 2010;140(6 Suppl):S77-80; discussion S86-91.

10. Weigang E, Parker J, Czerny M, Peivandi AA, Dorweiler B, Beyersdorf F, et al. Endovascular aortic arch repair after aortic arch de-branching. Ann Thorac Surg. 2009;87:603-7.

11. Szeto WY, Bavaria JE, Bowen FW, Woo EY, Fairman RM, Pochettino A. The hybrid total arch repair: brachiocephalic bypass and concomitant endovascular aortic arch stent graft placement. J Card Surg. 2007;22:97-102.
12. Kent WD, Wong JK, Herget EJ, Bavaria JE, Appoo JJ. An alternative approach to diffuse thoracic aortomegaly: on-pump hybrid total arch repair without circulatory arrest. Ann Thorac Surg. 2012;93:326-8.

13. Cao P, De Rango P, Czerny M, Evangelista A, Fattori R, Nienaber C, et al. Systematic review of clinical outcomes in hybrid procedures for aortic arch dissections and other arch diseases. J Thorac Cardiovasc Surg. 2012;144:1286-300.e2.

14. Kotelis D, Geisbüsch P, Attigah N, Hinz U, Hyhlik-Dürr A, Böckler D. Total vs hemiaortic arch transposition for hybrid aortic arch repair. J Vasc Surg. 2011;54: 1182-6.e2.

15. Lee CW, Beaver TM, Klodell CT Jr, Hess PJ Jr, Martin TD, Feezor RJ, et al. Arch debranching versus elephant trunk procedures for hybrid repair of thoracic aortic pathology. Ann Thorac Surg. 2011;91:465-71.

16. Hughes GC, Daneshmand MA, Balsara KR, Achneck HA, Sileshi B, Lee SM, et al. "Hybrid" repair of aneurysms of the transverse aortic arch: midterm results. Ann Thorac Surg. 2009;88:1882-7; discussion 1887-8.

17. Ergin MA, Galla JD, Lansman L, Quintana C, Bodian C, Griepp RB. Hypothermic circulatory arrest in operations on the thoracic aorta: determinants of stroke and early mortality. J Thorac Cardiovasc Surg. 1994;107:788-92.

18. Gutsche JT, Cheung AT, McGarvey ML, Moser WG, Szeto W, Carpenter JP, et al. Risk factors for perioperative stroke after thoracic endovascular repair. Ann Thorac Surg. 2007;84:1195-200.

19. Estrera AL, Miller CC 3rd, Porat EE, Huynh TT, Winnerkvist A, Safi HJ. Staged repair of extensive aortic aneurysms. Ann Thorac Surg. 2002;74:S1803-5; discussion S1825-32. 